INTERNATIONAL JOURNAL OF SCIENTIFIC RESEARCH

LEVEL OF AWARENESS, KNOWLEDGE AND ATTITUDE REGARDING RESEARCH AMONG POST GRADUATE TRAINEE DOCTORS IN TEACHING HOSPITALS IN KOLKATA

\title{
Clinical Research
}

Dr. Quency

Michael Dcosta

Dr. Pankaj Kumar Singh*

\section{Dr. Mohit \\ Bhatnagar}

\section{Dr. Akash Kumar}

\section{Dr. Abhraneel Guha}

Senior Resident, Department of Emergency Medicine, Peerless Hospital and B.K. Roy Research Center, Kolkata, India.

\section{Dr. Mandeep Joshi}

Junior Consultant, Department of Emergency Medicine, Peerless Hospital and B.K. Roy Research Center, Kolkata, India. ${ }^{*}$ Corresponding Author Junior Consultant, Department of General Medicine, Peerless Hospital and B.K. Roy Research Center, Kolkata, India.

Junior Consultant, Department of Emergency Medicine, Peerless Hospital and B.K. Roy Research Center, Kolkata, India.

Senior Resident, Department of General Medicine, Peerless Hospital and B.K. Roy Research Center, Kolkata, India

\section{Dr. Shreya Verma}

Senior Resident, Department of General Medicine, Peerless Hospital and B.K. Roy Research Center, Kolkata, India.

DNB General Medicine Trainee, Peerless Hospital and B.K. Roy Research Center, Kolkata, India.

\section{ABSTRACT}

Aims and objectives: In this study, we wanted to assess the awareness, knowledge, and attitudes regarding research among postgraduate trainee doctors in teaching hospitals of Kolkata and identify the measures that can be taken to improve the research practices of the postgraduate residents. Material and Methods: A questionnaire-based survey was carried out among Postgraduate trainee doctors (DNB \& MD PG residents) from teaching hospitals in Kolkata duration of the study was approximately 1 year between July 2018- June 2019. The questionnaire was designed based on guidelines of knowledge of research methodology, attitudes and practices towards research, and measures to improve research practices. Results: In the present study the level of awareness, knowledge, attitudes of 170 post-graduate trainee doctors from the clinical and pre/para clinical specialty was evaluated, difficulties faced by them in conducting research, and suggestions on how research can be promoted among PG residents was taken. Conclusion: The present study revealed that the residents from both clinical and para/clinical specialties had a fair knowledge about research. They had a positive attitude toward research, but they are unable to transform their knowledge and attitude into actual practices.

\section{KEYWORDS}

Clinical research, Research skills, Post-graduate doctor, Teaching hospital, Attitude, knowledge, postgraduate student, practice, research,

\section{INTRODUCTION}

Research comprises of work undertaken on a systemic basis to increase the stock of knowledge, including the knowledge of an individual, culture, and society and the use of this stock of knowledge to devise new applications. It is used to establish and confirm facts, reaffirm the results of previous work, solve new or existing problems, support theorems, or develop new theories. 1

It is important to find out postgraduate students' perceptions and attitudes towards their thesis work to identify motivating factors/problems among them. As thesis forms the first stepping stone for them in medical science, evaluation of these factors can be of great help in cultivating a positive attitude and interest toward research in the field of medicine.

It was felt that the existing level of knowledge, awareness, and attitudes towards research among these doctors who already are conducting at least one research study for their dissertation should be evaluated. So, we decided to undertake a cross-sectional study to assess and evaluate the knowledge, awareness, and attitudes of postgraduate resident doctors in teaching hospitals of Kolkata regarding research skills including difficulties in conducting research and measures that can be taken to solve them. This will identify gaps in the development of research orientation in the healthcare sector.

Different studies showed that the data regarding knowledge, attitudes, and practices toward medical research among postgraduate students pursuing postgraduate studies in India is lacking. It is felt that the existing level of knowledge and awareness among the resident doctors who have already conducted/are conducting at least one research study for their dissertation should be evaluated. Hence, the present study was carried out to assess the research-related knowledge, attitude, and practices of post-graduate trainee doctors in teaching hospitals of Kolkata.

\section{MATERIALS AND METHODS}

Site of study: Postgraduate teaching hospitals in Kolkata (both Government \&Private, DNB \& MD)

Study Population: Clinical and paraclinical Postgraduate trainee doctors.

Study Design: a cross-sectional multicentre, prospective survey was conducted using a structured and pre-validated questionnaire.

Duration of study: The duration of the study was approximately 1 year between July 2018- June 2019

Inclusion Criteria: Postgraduate trainee doctors (DNB \& MD PG residents) from teaching hospitals in Kolkata during the period of study.

Exclusion Criteria: Non-training medical officers working in teaching hospitals of Kolkata. Postgraduate diploma resident doctors where research and thesis are not included in the syllabus.

Data Collection: The questionnaire was designed based on guidelines of knowledge of research methodology, attitudes, and practices 
towards research and measures to improve research practices and drafted in the English language.

Statistical Methods: A questionnaire-based survey was carried out among PG resident doctors from teaching hospitals from Kolkata through an electronic survey using the web-based software "survey monkey" (http://www.surveymonkey.com) which allowed secure, anonymous distribution of questionnaire via the internet.

Statistical analysis: A total of 170 postgraduate trainee doctors were enrolled in this study and data was analyzed. Descriptive statistical analysis was performed to calculate the means with corresponding standard deviations (S.D.). Using this software, basic cross-tabulation and associations were performed. Chi-square test was used to test the association of different study variables. Z-test (Standard Normal Deviate) was used to test the significant difference between the two proportions. $\mathrm{p}<0.05$ was considered statistically significant.

\section{RESULTS}

\section{Demography}

Table 1: Distribution of age of the participants

\begin{tabular}{|c|c|c|}
\hline Age Group (in years) & Number & $\mathbf{\%}$ \\
\hline $\mathbf{2 3} \mathbf{- 2 5}$ & 32 & $18.0 \%$ \\
\hline $\mathbf{2 6} \mathbf{- 2 8}$ & 76 & $76.4 \%$ \\
\hline$>\mathbf{2 8}$ & 62 & $5.6 \%$ \\
\hline Total & 170 & $100.0 \%$ \\
\hline Mean \pm s.d. & $27.81 \pm 2.69$ & \\
\hline Median & 27 & \\
\hline Range & $23-33$ & \\
\hline
\end{tabular}

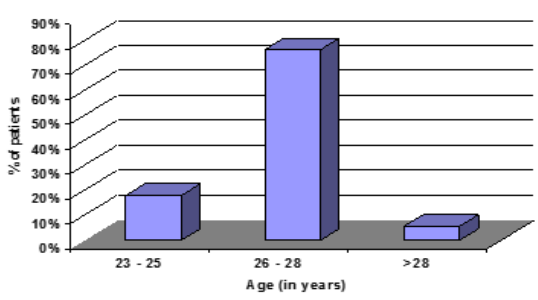

Figure 1: Distribution of age of the participants

The mean age (mean \pm s.d.) of the participants was $27.81 \pm 2.69$ years with range $23-33$ years and the median age was 27 years

Table 2: Gender Distribution of the Enrolled PGT Doctors

\begin{tabular}{|c|c|c|}
\hline Gender & Number & \% \\
\hline Male & 99 & $58.2 \%$ \\
\hline Female & 71 & $41.8 \%$ \\
\hline Total & 170 & $100.0 \%$ \\
\hline Male:Female & $1.4: 1.0$ & \\
\hline
\end{tabular}

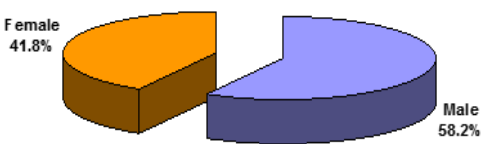

\section{पMale QF emale}

Figure 1: Gender Distribution of the Enrolled PGT Doctors Majority of the participants $(58.2 \%)$ were males.

Table 3: Distribution of field of specialization of the participants

\begin{tabular}{|c|c|c|}
\hline Field of specialization & Number & \% \\
\hline Clinical & 103 & $60.6 \%$ \\
\hline Pre- and Para- Clinical & 67 & $39.4 \%$ \\
\hline Total & 170 & $100.0 \%$ \\
\hline
\end{tabular}

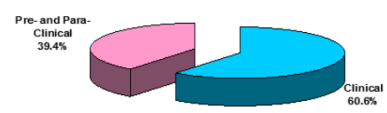

Figure 3: Distribution of field of specialization of the participants

$60.6 \%$ of the respondents were from clinical field and $39.4 \%$ were from pre/ para-clinical field.

Assessment of knowledge and awareness about medical research among study subjects

Table 5: Answer to the question- what is the highest level of evidence of available literatures?

\begin{tabular}{|c|c|c|}
\hline $\begin{array}{c}\text { Highest level of evidence of available } \\
\text { literatures }\end{array}$ & Number & $\%$ \\
\hline Case series & 31 & $18.2 \%$ \\
\hline Randomized control trials & 139 & $81.8 \%$ \\
\hline Total & 170 & $100.0 \%$ \\
\hline \\
\hline
\end{tabular}

Figure 5: Answer to the question- what is the highest level of evidence of available literatures?

$81.8 \%$ of the respondents answered correctly that randomized control trials are the highest level of evidence of available literatures which was significantly higher than that of the incorrect answer $(18.2 \%)(\mathrm{Z}=$ $9.05 ; \mathrm{p}<0.0001)$

Table 6: Answer by the respondents regarding full form of MEDLINE

\begin{tabular}{|c|c|c|}
\hline Full form of MEDLINE & Number & \% \\
\hline $\begin{array}{c}\text { Medical literature analysis and retrieval } \\
\text { system online }\end{array}$ & 116 & $68.2 \%$ \\
\hline $\begin{array}{c}\text { Medical knowledge analysis and research } \\
\text { system }\end{array}$ & 54 & $31.8 \%$ \\
\hline Total & 170 & $100.0 \%$ \\
\hline $\begin{array}{c}\text { Medical } \\
\text { knowled } \\
\text { analysisas and } \\
\text { research } \\
\text { system } \\
\text { 31.8\% }\end{array}$ \\
\hline
\end{tabular}

Figure 6: Answer by the respondents regarding full form of MEDLINE

$68.2 \%$ of the respondents responded with correct answer which was significantly higher than that of incorrect answer (31.8\%) $(Z=5.09$; $\mathrm{p}<0.0001)$

Table 7: Answer by the respondents regarding method of estimation of confidence interval

\begin{tabular}{|c|c|c|}
\hline What is estimated by confidence interval & Number & $\%$ \\
\hline Standard deviation & 106 & $62.4 \%$ \\
\hline $\begin{array}{l}\text { True value of an unknown population } \\
\text { parameter }\end{array}$ & 64 & $37.6 \%$ \\
\hline Total & 170 & $100.0 \%$ \\
\hline 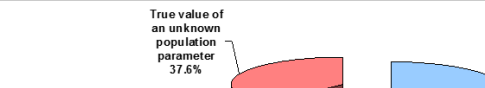 & & \\
\hline
\end{tabular}

$\square$ Standard deviation $\square$ True value of an unknown population parameter

Figure 7: Answer by the respondents regarding method of estimation of confidence interval 
$62.4 \%$ of the respondents responded with correct answer which was significantly higher than that of incorrect answer $(37.6 \%)(Z=3.39$; $\mathrm{p}<0.0001)$

Table 8: Answer by the respondents regarding authority responsible for approval of drug trials in India

\begin{tabular}{|c|c|c|}
\hline $\begin{array}{c}\text { Authority responsible for approval of drug } \\
\text { trials in India }\end{array}$ & Number & $\%$ \\
\hline Drug technical Advisory Board (DTAB) & 94 & $55.3 \%$ \\
\hline MCI & 76 & $44.7 \%$ \\
\hline Total & 170 & $100.0 \%$ \\
\hline $\begin{array}{c}\text { MCI } \\
44.7 \%\end{array}$ \\
\hline
\end{tabular}

GDrug technical Advisory Board (DTAB) $\square \mathrm{MCl}$

Figure 8: Answer by the respondents regarding authority responsible for approval of drug trials in India

$55.3 \%$ of the respondents responded with correct answer which was higher than that of incorrect answer but it was not significant $(44.7 \%)$ $(\mathrm{Z}=1.41 ; \mathrm{p}=0.16)$.

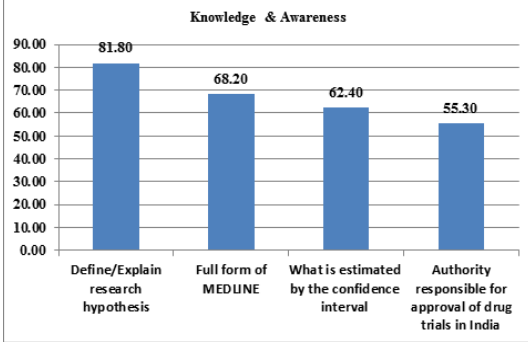

Figure 9: Proportion of Correct Answers to the Knowledge Questions

\section{Attitude towards Research:}

Table 9: Answer by the respondents to the question- Should training for research methodology be made compulsory for PG students?

\begin{tabular}{|c|c|c|}
\hline $\begin{array}{c}\text { Should training for research } \\
\text { methodology be made compulsory for } \\
\text { PG students? }\end{array}$ & Number & $\%$ \\
\hline Yes & 155 & $91.2 \%$ \\
\hline No & 15 & $8.8 \%$ \\
\hline Total & 170 & $100.0 \%$ \\
\hline
\end{tabular}

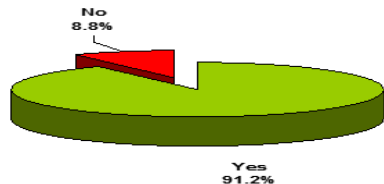

Dres DNo

Figure 10: Answer by the respondents to the question- Should training for research methodology be made compulsory for PG students?

$91.2 \%$ of the respondents responded that training for research methodology should be made compulsory for PG students which were higher than those who disagreed. $(8.8 \%)(Z=11.59 ; \mathrm{p}<0.0001)$.

Table 10: Answer by the respondents to the question- does undertaking of research caused increasing burden on already overworked doctors?

Does undertaking of research caused increasing burden on already overworked doctors?

\begin{tabular}{|c|c|c|}
\hline Yes & 122 & $71.8 \%$ \\
\hline No & 48 & $28.2 \%$ \\
\hline Total & 170 & $100.0 \%$ \\
\hline
\end{tabular}

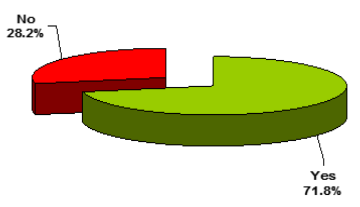

GYes $\square N_{0}$

Figure 11: Answer by the respondents to the question- does undertaking of research caused increasing burden on already overworked doctors?

$71.8 \%$ of the respondents felt thatundertaking of research caused increasing burden on already overworked doctors which was significantly higher than those who did not agree to the statement. $(28.2 \%)(Z=6.22 ; p<0.0001)$

Table 11: Distribution of answer by the respondent's whether undertaking of research caused increasing burden on already overworked doctors and the respondents of the two groups

\begin{tabular}{|c|c|c|c|}
\hline $\begin{array}{c}\text { Undertaking of } \\
\text { research caused } \\
\text { increasing burden on } \\
\text { already overworked } \\
\text { doctors }\end{array}$ & $\begin{array}{c}\text { Clinical } \\
(\mathbf{n}=\mathbf{1 0 3})\end{array}$ & $\begin{array}{c}\text { Pre- and Para- } \\
\text { Clinical } \\
(\mathbf{n}=\mathbf{6 7})\end{array}$ & Total \\
\hline Yes & 81 & 41 & 122 \\
Row \% & 66.4 & 33.6 & 100.0 \\
Col \% & 78.6 & 61.2 & 71.8 \\
\hline No & 22 & 26 & 48 \\
Row \% & 45.8 & 54.2 & 100.0 \\
Col \% & 21.4 & 38.8 & 28.2 \\
\hline TOTAL & 103 & 67 & 170 \\
Row \% & 60.6 & 39.4 & 100.0 \\
Col \% & 100.0 & 100.0 & 100.0 \\
\hline
\end{tabular}

$\mathrm{X}^{2}=6.09 ; \mathrm{p}=0.0135$ S-Significant

Chi-square $\left(\mathrm{x}^{2}\right)$ test showed that there was a significant association among the respondents on the statement thatundertaking of research caused increasing burden on already overworked doctors and the respondents of the two groups $(\mathrm{p}=0.0135)$. The proportion of clinicians $(78.6 \%)$ with answer that research caused increasing burden on already overworked doctors was significantly higher than that of the pre-and para-clinicians $(61.2 \%)(Z=2.77 ; \mathrm{p}=0.00054)$.

Table 12: Answer by the respondents to the question - Will you be interested in carrying out research in future if it was not made compulsory?

\begin{tabular}{|c|c|c|}
\hline $\begin{array}{c}\text { Will you be interested in carrying out } \\
\text { research in future if it was not made } \\
\text { compulsory? }\end{array}$ & Number & $\%$ \\
\hline Yes & 114 & $67.1 \%$ \\
\hline No & 56 & $32.9 \%$ \\
\hline Total & 170 & $100.0 \%$ \\
\hline Noo & \\
\hline
\end{tabular}

QYes पN0

Figure 12: Answer by the respondents to the question - Will you be interested in carrying out research in future if it was not made compulsory?

$67.1 \%$ of the respondents said that they would be interested in carrying out research in future if it was not made compulsory which was significantly higher than that of the opinion for non-compulsion $(32.9 \%)(Z=4.81 ; \mathrm{p}<0.0001)$. 
Table 13: Distribution of answer by the respondents regarding interest in carrying out compulsory research in future and the respondents of the two groups

\begin{tabular}{|c|c|c|c|}
\hline $\begin{array}{c}\text { Interest in carrying out } \\
\text { compulsory research in } \\
\text { future. }\end{array}$ & $\begin{array}{c}\text { Clinical } \\
(\mathbf{n = 1 0 3 )}\end{array}$ & $\begin{array}{c}\text { Pre- and Para- } \\
\text { Clinical } \\
(\mathbf{n = 6 7 )}\end{array}$ & Total \\
\hline Yes & 69 & 45 & 114 \\
Row \% & 60.5 & 39.5 & 100.0 \\
Col \% & 67.0 & 67.2 & 67.1 \\
\hline No & 34 & 22 & 56 \\
Row \% & 60.7 & 39.3 & 100.0 \\
Col \% & 33.0 & 32.8 & 32.9 \\
\hline TOTAL & 103 & 67 & 170 \\
Row \% & 60.6 & 39.4 & 100.0 \\
Col \% & 100.0 & 100.0 & 100.0 \\
\hline
\end{tabular}

$\mathrm{X}^{2}=0.0006 ; \mathrm{p}=0.98 \quad$ NS-Not Significant

Chi-square $\left(\mathrm{x}^{2}\right)$ test showed that there was no significant association amongthe respondents regarding interest in carrying out compulsory research in future and the respondents of the two groups $(\mathrm{p}=0.98)$.

Thus the answers were more or less equally distributed among the respondents of the two groups. However, the proportion of clinicians $(67.0 \%)$ who had shown interest in carrying out compulsory research in future was lower than that of the pre-and para-clinicians (67.2\%).

Table 14: Answer by the respondents to the question - should research time be allotted separately while planning PG curriculum?

\begin{tabular}{|c|c|c|}
\hline $\begin{array}{c}\text { Should research time be allotted separately } \\
\text { while planning PG curriculum? }\end{array}$ & Number & $\%$ \\
\hline Yes & 164 & $96.5 \%$ \\
\hline No & 6 & $3.5 \%$ \\
\hline Total & 170 & $100.0 \%$ \\
\hline
\end{tabular}

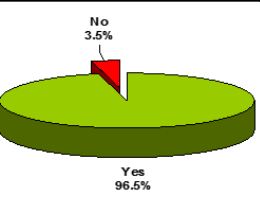

GYes घNO

Figure 13: Answer by the respondents to the question - should research time be allotted separately while planning PG curriculum?

$96.5 \%$ of the respondents agreed that allocation of separate research time must be considered in planning PG curriculum which was significantly higher $(Z=13.29 ; \mathrm{p}<0.0001)$.

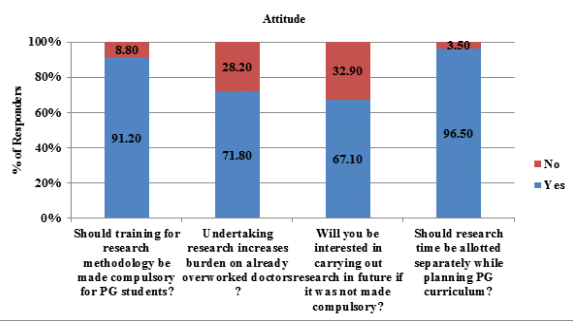

Figure 14: Proportion of Correct Answers to the Attitude Questions

\section{Practices}

Table 15: Answer by the respondents regarding willingness to participate in workshop on research methodology

\begin{tabular}{|c|c|c|}
\hline $\begin{array}{c}\text { Are you willing to participate in } \\
\text { workshops on Research } \\
\text { methodology? }\end{array}$ & Number & \% \\
\hline Yes & 122 & $71.8 \%$ \\
\hline No & 48 & $28.2 \%$ \\
\hline Total & 170 & $100.0 \%$ \\
\hline
\end{tabular}

Figure 15: Answer by the respondents regarding willingness to participate in workshop on research methodology

$71.8 \%$ of the respondents had shown willingness to participate in workshop on research methodology which was significantly higher than those who were not willing to participate in workshops $(28.2 \%)$ $(\mathrm{Z}=6.22 ; \mathrm{p}<0.0001)$

Table 16: Answer by the respondents regarding research publication in any journal till date

\begin{tabular}{|c|c|c|}
\hline $\begin{array}{c}\text { Do you have any research publication } \\
\text { in any journals till date }\end{array}$ & Number & $\%$ \\
\hline Yes & 24 & $14.1 \%$ \\
\hline No & 146 & $85.9 \%$ \\
\hline Total & 170 & $100.0 \%$ \\
\hline
\end{tabular}

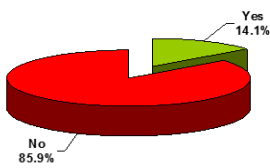

TYes aNo

Figure 16: Answer by the respondents regarding research publication in any journal till date

Only $14.1 \%$ of the respondents had authorship of research publication in any indexed journal till date.

Table 17: Distribution of answer by the respondents regarding authorship of research publication in any indexed journal till date and the respondents of the two groups

\begin{tabular}{|c|c|c|c|}
\hline $\begin{array}{c}\text { Authorship of research } \\
\text { publication in any indexed } \\
\text { journal till date }\end{array}$ & $\begin{array}{c}\text { Clinical } \\
(\mathbf{n}=\mathbf{1 0 3})\end{array}$ & $\begin{array}{c}\text { Pre- and Para- } \\
\text { Clinical } \\
(\mathbf{n}=\mathbf{6 7})\end{array}$ & Total \\
\hline Yes & 12 & 12 & 24 \\
Row \% & 50.0 & 50.0 & 100.0 \\
Col \% & 11.7 & 17.9 & 14.1 \\
\hline No & 91 & 55 & 146 \\
Row \% & 62.3 & 37.7 & 100.0 \\
Col \% & 88.3 & 82.1 & 85.9 \\
\hline TOTAL & 103 & 67 & 170 \\
Row \% & 60.6 & 39.4 & 100.0 \\
Col \% & 100.0 & 100.0 & 100.0 \\
\hline
\end{tabular}

$\mathrm{X}^{2}=1.31 ; \mathrm{p}=0.25 \mathrm{~N}$ S- Not Significant

Chi-square $\left(\mathrm{x}^{2}\right)$ test showed that there was no significant association withthe respondents regarding authorship of research publication in any indexed journal till date and the respondents of the two groups $(\mathrm{p}=0.25)$.

The proportion of clinicians $(11.7 \%)$ who had authorship of research publication in any indexed journal till date was lower than that of the pre-and para-clinicians $(17.9 \%)$.

Table 18: Answer by the respondents regarding presentation of poster/research paper in a state/national conference

\begin{tabular}{|c|c|c|}
\hline $\begin{array}{c}\text { Have you presented poster/research paper } \\
\text { in a state/national conference? }\end{array}$ & Number & $\%$ \\
\hline Yes & 32 & $18.8 \%$ \\
\hline No & 138 & $81.2 \%$ \\
\hline Total & 170 & $100.0 \%$ \\
\hline
\end{tabular}

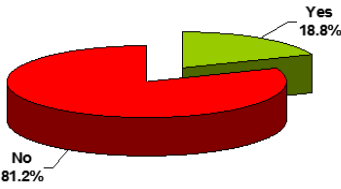

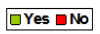

Figure 17: Answer by the respondents regarding presentation of poster/research paper in a state/national conference 
Only $18.8 \%$ of the respondents had presented any poster/research paper in a state/national conference.

Table 19: Distribution of answer by the respondents regarding presentation of poster/research paper in a state/national conference till date and the respondents of the two groups

\begin{tabular}{|c|c|c|c|}
$\begin{array}{c}\text { Presentation of } \\
\text { poster/research paper in a } \\
\text { state/national conference till } \\
\text { date }\end{array}$ & $\begin{array}{c}\text { Clinical } \\
(\mathbf{n}=\mathbf{1 0 3})\end{array}$ & $\begin{array}{c}\text { Pre- and } \\
\text { Para- Clinical } \\
(\mathbf{n}=67)\end{array}$ & Total \\
\hline Yes & 21 & 11 & 32 \\
Row \% & 65.6 & 34.4 & 100.0 \\
Col \% & 20.4 & 16.4 & 18.8 \\
\hline No & 82 & 56 & 138 \\
Row \% & 59.4 & 40.6 & 100.0 \\
Col \% & 79.6 & 83.6 & 81.2 \\
\hline TOTAL & 103 & 67 & 170 \\
Row \% & 60.6 & 39.4 & 100.0 \\
Col \% & 100.0 & 100.0 & 100.0 \\
\hline
\end{tabular}

$\mathrm{X}^{2}=1.31 ; \mathrm{p}=0.25$ N S- Not Significant

Chi-square $\left(\mathrm{x}^{2}\right)$ test showed that there was no significant association amongthe respondents regarding presentation of poster/research paper in a state/national conference till date and the respondents of the two groups $(\mathrm{p}=0.25)$.

The proportion of clinicians (20.4\%) had presentation of poster/research paper in a state/national conference till date was higher than that of the pre-and para-clinicians (16.4\%).

Table 20: Answer by the respondents regarding experience of writing research paper/case report till date

\begin{tabular}{|c|c|c|}
\hline $\begin{array}{c}\text { Experience of writing research } \\
\text { paper/case report till date }\end{array}$ & Number & $\%$ \\
\hline Yes & 94 & $55.3 \%$ \\
\hline No & 76 & $44.7 \%$ \\
\hline Total & 170 & $100.0 \%$ \\
\hline
\end{tabular}
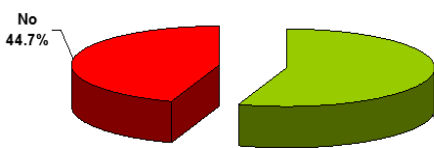

Yes

$\square$ Yes $\square$ No

Figure 18: Answer by the respondents regarding experience of writing research paper/case report till date

$55.3 \%$ of the respondents had experience of writing research paper/case report till date which was significantly higher $(Z=1.41$; $\mathrm{p}=0.16$ ).

Table 21: Distribution of answer by the respondents regarding experience of writing research paper/case report till date and the respondents of the two groups

\begin{tabular}{|c|c|c|c|}
\hline $\begin{array}{c}\text { Experience of writing } \\
\text { research paper/case } \\
\text { report till date }\end{array}$ & $\begin{array}{c}\text { Clinical } \\
(\mathbf{n}=103)\end{array}$ & $\begin{array}{c}\text { Pre- and Para- } \\
\text { Clinical } \\
(\mathbf{n}=\mathbf{6 7})\end{array}$ & Total \\
\hline Yes & 51 & 43 & 94 \\
Row \% & 54.3 & 45.7 & 100.0 \\
Col \% & 49.5 & 64.2 & 55.3 \\
\hline No & 52 & 24 & 76 \\
Row \% & 68.4 & 31.6 & 100.0 \\
Col \% & 50.5 & 35.8 & 44.7 \\
\hline TOTAL & 103 & 67 & 170 \\
Row \% & 60.6 & 39.4 & 100.0 \\
Col \% & 100.0 & 100.0 & 100.0 \\
\hline
\end{tabular}

$\mathrm{X}^{2}=3.53 ; \mathrm{p}=0.06$ NS- Not Significant

Chi-square $\left(\mathrm{x}^{2}\right)$ test showed that there was no significant association the respondents regarding experience of writing research paper/case report till date and the respondents of the two groups $(\mathrm{p}=0.06)$.
The proportion of clinicians $(49.5 \%)$ who had experience of writing research paper/case report till date was lower than that of the pre-and para-clinicians $(64.2 \%)$

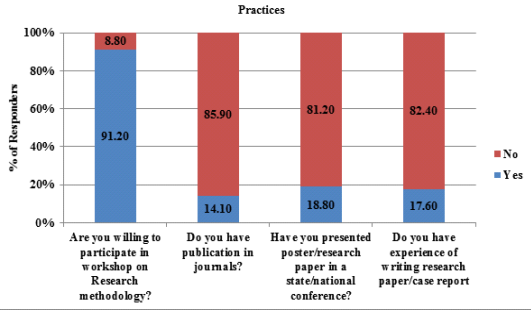

Figure 10: Proportion of Correct Answers to the Practices Questions

\section{DISCUSSION}

We tried to find in our study the level of awareness and knowledge of research among post-graduate doctors in Kolkata and whether the current methods of training and facilities are adequate to generate interest among students to do their post-graduation research. Measures that can be taken to promote research were also suggested. Our study showed various key findings that would be of interest to medical educators and policymakers.

In the present study the level of awareness, knowledge, attitudes of 170 post-graduate trainee doctors from the clinical and pre/para clinical specialty was evaluated, difficulties faced by them in conducting research, and suggestions on how research can be promoted among PG residents was taken.

Among the participants, the majority of the participants were age between $26-28$ years. The majority of the participants were males. Out of the enrolled doctors, $60.6 \%$ were from clinical specialty and $39.4 \%$ from the para clinical specialty.

In regards to questions on knowledge $\&$ awareness, the majority of the respondents (mean knowledge score 66.9\%) of both specialties answered most of the questions correctly. Thus most of the participants had adequate knowledge regarding research methodology.

In a similar study done by Moges T. et al. out of 345 residents, the mean Knowledge score was $34.6 \% .2$ Pallamparthy S. et al, in their study, found that out of the 300 participants, about $70 \%$ of the participants showed adequate research knowledge. 3 In a study done by Purushottam A. Giri et al. out of 116 participants, only $19.2 \%$ of the participants had adequate knowledge regarding research. 4 In a study done by Dattaray P. et al., out of 100 participants, $60 \%$ of the participants showed adequate knowledge regarding research.5

In the present study, the majority of respondents $(91.2 \%)$ felt that training for research methodology should be made compulsory for PG students, out of these $89.3 \%$ residents were from clinical specialty and $94 \%$ were from the pre/para clinical specialty. $71.8 \%$ of the residents felt that undertaking research increases the burden on already overworked doctors. A higher proportion of residents from the clinical specialty felt that research caused an increasing burden on already overworked doctors. $67.1 \%$ of the respondents said that they would be interested in researching the future if it was not made compulsory. However, the proportion of clinicians $(67.0 \%)$ who had shown interest in carrying out compulsory research in the future was lower than that of the pre-and para-clinicians $(67.2 \%) .96 .5 \%$ of the respondents agreed that the allocation of separate research time must be considered in planning the PG curriculum.

Thus although residents both clinical and para/pre-clinical felt that undertaking research increases the burden on overworked doctors, they showed a positive attitude towards researching if research time was allotted separately while planning the PG curriculum. They also suggested that research methodology should be included as a syllabus for PG students.

A study was done by Dattatray B. Pawar et al., also showed that resident doctors demonstrated fairly good knowledge and positive attitude toward research.5 Morges T. et al. found that Participants' attitude towards research was positive, but their knowledge of research made their practice inadequate. 2 Two studies that were carried out in 
Canada and Pakistan reflected a contrasting attitude of residents who felt that a majority of time in residency should be spent learning the clinical aspects of their specialty and they were unwilling to sacrifice personal time for research ${ }^{6,7}$.

In the present study, $71.8 \%$ of the respondents showed a willingness to participate in workshops on research methodology. Although a majority of the postgraduate residents wished to get involved in research, very few had participated in research work, other than the mandatory dissertation project. Only $14.1 \%$ of the respondents had authorship of research publication in any indexed journal to date. The proportion of residents from the clinical specialty who had authorship in any research publication was lower than that of the pre-and paraclinicians.

In this study, only $18.8 \%$ of the respondents had presented any poster/research paper in a state/national conference. Out of these, $20.4 \%$ of residents from clinical and $16.4 \%$ from pre/paraclinical specialty had the presentation of poster/research paper. $55.3 \%$ of the respondents had the experience of writing research paper/case report to date. The proportion of clinicians who had the experience of writing research paper/case report to date was lower than that of the pre-and para-clinicians.

In a study by Dattatray B. Pawar et al., as low as $4 \%$ of the study participants had published articles and $28 \%$ had presented research papers at national conferences5. In another study done by Purushottam A. Giri et al. it was found that out of 116 postgraduate students, $61.2 \%$ students had previous experience of research projects, whereas $31.1 \%$ had presented papers at the institute, national, or international levels. ${ }^{4}$

\section{CONCLUSION}

The present study revealed that the residents from both clinical and para/clinical specialties had a fair knowledge about research. They had a positive attitude toward research, but they are unable to transform their knowledge and attitude into actual practices. Low research practices in the context of positive attitude may be due to various issues such as lack of time, lack of research curriculum, inadequate facilities for conducting research, inadequate support from mentors/ guides. Lower research output among clinical residents as compared to pre/para clinical residents may be attributed to long continuous duty hours giving them inadequate time to take part in research activities.

The medical council of India, the National Board of Examinations (NBE), and teaching hospitals should take the necessary measures to promote research. As lack of time due to clinical work was cited as the main obstacle by a majority of resident doctors, specific time for research should be allocated during post-graduate residency.

Positive attitude towards research has been a recurring finding in almost all studies from within and outside the country and gives hope that given further changes in the right direction the education scenario will see quality research work being taken up by doctors and the Indian contribution to literature and scientific discoveries will increase manifold.

\section{REFERENCES}

1. Cheetham A. Growing a research culture. Address to Academic Senate, Friday. 2007 May 4:1-7.

2. Moges T, Deribew M, Mariam DH. Knowledge, attitude, and practice of residents in medical research and barriers: A cross-sectional survey at Tikur Anbessa Specialized Hospital. Ethiopian Journal of Health Development. 2017;31(4):259-65.

3. Pallamparthy S, Basavareddy A. Knowledge, attitude, practice, and barriers toward research among medical students: A cross-sectional questionnaire-based survey. Perspectives in clinical research. 2019 Apr;10(2):73

4. Purushottam A. Giri VBB, Deepak B. Phalke .Knowledge, Attitude and Practices towards Medical Research amongst the Postgraduate Students of Pravara Institute of Medical Sciences University of Central India. . J Family Med Prim Care 2014;3 (1):22-4.

5. Pawar DB, Gawde SR, Marathe PA. Awareness about medical research among resident doctors in a tertiary care hospital: A cross-sectional survey. Perspect Clin Res. 2012; 3: $57-61$

6. Chaturvedi S, Aggarwal OP. Training interns in population-based research: learners' feedback from 13 consecutive batches from a medical school in India. Medical education. 2001 Jun 1;35(6):585-9.

7. Soe HH, Than NN, Lwin H, Htay MN, Phyu KL, Abas AL. Knowledge, attitudes, and barriers toward research: The perspectives of undergraduate medical and dental students. Journal of education and health promotion. 2018;7. 